\title{
Evidence-based review of oral traditional Chinese medicine compound recipe administration for treating weight drop- induced experimental traumatic brain injury
}

\author{
Bo Yang ${ }^{1}$, Zhe Wang ${ }^{2}$, Chenxia Sheng ${ }^{2}$, Yang Wang ${ }^{1}$, Jing Zhou' ${ }^{1}$ Xin-gui Xiong ${ }^{1}$ and Weijun Peng ${ }^{2 *}$ (1)
}

\begin{abstract}
Background: Recently, a number of studies conducted and published in China have suggested that traditional Chinese medicine compound recipe (TCMCR) may be beneficial in the treatment of experimental traumatic brain injury (TBI). In this study, we conducted a systematic review and meta-analysis of the efficacy of TCMCR in TBI model with weight drop method to provide robust evidence on the effects of TCMCR and to determine whether TCMCR can be recommended for routine treatment or considered as a standard treatment for TBI.

Methods: We identified eligible studies by searching five electronic databases on April 1, 2014, and pooled the data using the random-effects model. Results were reported in terms of standardized mean difference (SMD). We also calculated statistical heterogeneity, evaluated the studies' methodological quality and investigated the presence of publication bias.

Results: Totally, 187 relevant publications were searched from databases, 25 of which met our inclusion criteria. The overall methodological quality of the most studies was poor, and there was evidence of statistical heterogeneity among studies along with small-study effects. Meta-analysis showed statistically significant effects indicating that TCMCR has a beneficial effect on TBI.

Conclusions: Despite the limitations, we concluded that TCMCR may reduce brain water content, improve BBB permeability, and decrease TNF-a/NO expression after experimental TBI in terms of overall efficacy. However, our review also indicates that more well-designed and well-reported animal studies are needed.
\end{abstract}

Keywords: Meta-analysis, Systematic review, Traumatic brain injury, Traditional Chinese medicine compound recipe

\section{Background}

Traumatic brain injury (TBI) remains the leading cause of long-term disability in individuals under 35 years worldwide [1], severely affects the quality of life of surviving patients and brings a significant social and economic burden. However, there is currently no effective pharmacological interventions options for TBI [2].

\footnotetext{
* Correspondence: pengweijun1987@gmail.com

${ }^{2}$ Department of Integrated Chinese and Western Medicine, The Second Xiangya Hospital, Central South University, No.139 Middle Renmin Road, Changsha, Hunan 410011 , P.R. China

Full list of author information is available at the end of the article
}

Because research aimed at therapy development has focused almost exclusively on single therapies, all of which have failed in multicenter clinical trials [3]. Fortunately, the focus of research has recently shifted to modify multiple targets, either through combination therapies or through the use of single agents that modulate multiple key secondary events following TBI $[4,5]$.

For thousands of years, traditional Chinese medicine (TCM) has been widely practice in China, and holds a key role in maintaining the health of the Chinese population, merits far greater attention from researchers because of its diverse pharmacological functions and 
targets, which can provide improved treatment of complex diseases by its ability to aim at several targets simultaneously [5]. The traditional Chinese medicine compound recipe (TCMCR), the main form of TCM drug treatment, may represent an ideal source for developing safe and effective agents for TBI treatment because it contains $\geq 2$ Chinese herbs, and therefore more closely conforms to TCM theories and more accurately reflects the characteristics of TCM than does the administration of a single herb [6]. Recently, a number of studies conducted and published in China have suggested that TCMCR may be beneficial in TBI treatment and rehabilitation [7-11]. However, it is uncertain whether robust evidence exists on the effects of TCMCR or whether TCMCR can be recommended either for routine treatment or considered as a standard treatment for TBI. Moreover, a systematic review and meta-analysis of the efficacy of TCMCR in treating TBI has not yet been investigated in experimental animal studies.

Therefore, the primary aim of the present study was to conduct a systematic review and meta-analysis to investigate in an unbias manner whether the evidence from experimental studies indicated a beneficial effect of TCMCR in the treatment of TBI in animal models.

\section{Methods}

\section{Literature search}

All studies reporting the efficacy of TCMCR in animal TBI models prior to April 1, 2014 were included. Articles were searched in the following databases: PubMed, ScienceDirect, CNKI, Wan-Fang Data, and Vip. The key search terms are summarized in Table 1 and were kept broad to capture all potentially relevant articles. In addition, the reference lists of all relevant articles were searched for further relevant publications.

\section{Study selection}

Three investigators assessed the records to assess for eligibility based on title, abstracts. The copies of all

Table 1 Key search terms used in database searches

\begin{tabular}{ll}
\hline Traumatic brain injury & traditional Chinese medicine compound recipe \\
Traumatic brain injury & traditional Chinese medicine compound recipe \\
Traumatic brain injuries & traditional Chinese medicine recipe \\
Head injury & traditional Chinese herb medicine \\
Head injuries & traditional Chinese medicine \\
Brain injury & Chinese herb medicine \\
Brain injuries & Chinese medicine \\
Injury brain & herb medicine \\
Injuries brain & TCMCR \\
Head trauma & TCM \\
TBl & \\
\hline
\end{tabular}

relevant articles were obtained and further assessed whether each met the prespecified inclusion criteria, the details of which are presented in Table 2. Disagreements among investigators were resolved by consensus after discussion.

\section{Data extraction}

Two investigators independently extracted details of each included studies including the animal species used, type of TBI model, treatment groups, time/dose of drug administration, anesthetic used, and the main outcomes. Information on sample sizes and substances used as experimental and control treatments was also extracted. Disagreements were resolved through consultation with a third party author.

When sufficient data were not available, authors were contacted and requested to provide missing data. The digital ruler software was used to estimate numerical values from the graphs, if no reply was received. And the study was excluded from the meta-analysis, when the required data were not obtainable.

\section{Study quality}

The methodological quality of each included studies was assessed based on a 10-point quality checklist modified from the CAMARADES study as previously described, with minor modifications [12, 13], comprising (1) publication in a peer-reviewed journal; (2) random group allocation; (3) blinded induction of brain injury; (4) blinded assessment of outcome; (5) monitoring of physiological parameters including temperature; (6) sample size calculation; (7) compliance with animal welfare regulations; (8) avoidance of anesthetics with marked intrinsic neuroprotective properties (ketamine); (9) statement of potential conflicts of interest; (10) use of accurate/suitable/adequate animal models.

One point was given for written evidence of the quality criteria.

\section{Statistical analysis}

Data were processed as described previously [14]. Briefly, for the meta-analysis, results were calculated as standardized mean difference (SMD), and $95 \%$ confidence intervals (CI) with random-effects model to avoid heterogeneity were used to assay differences of the global estimate effect [13]. The Cochran's Q-statistic was used to assess within- and between-study variation or heterogeneity $[15,16]$. Heterogeneity was quantified with the $I^{2}$ metric, with higher values denoting a greater degree of heterogeneity. $I^{2}$ values $\leq 50 \%$ indicate acceptable heterogeneity among studies [17]. For studies comparing different doses and/or timing of drug administration with a single control group, we pooled data from all experimental groups for comparison with the control 
Table 2 Criteria for the inclusion/exclusion of studies

\begin{tabular}{|c|c|}
\hline Inclusion criteria & Exclusion criteria \\
\hline 1. Published in peer-viewed journal & 1. Non-published studies and dissertations \\
\hline 2. Was published in English or Chinese & 2. No control group \\
\hline 3. TCMCR was administered orally & $\begin{array}{l}\text { 3. TCMCR administered in other methods (e.g. Intraperitoneally, } \\
\text { subcutaneously, etc.) }\end{array}$ \\
\hline 4. Experimental TBI was induced in rodents & 5. Examined other types of animals (e.g. sheep, cat, dog etc.) \\
\hline $\begin{array}{l}\text { 5. Had a TBI treatment group that was treated with TCMCR and TBI } \\
\text { control group that was administered a placebo following injury }\end{array}$ & $\begin{array}{l}\text { 6. Administration of traditional Chinese injection or a single } \\
\text { Chinese herb in the treatment group }\end{array}$ \\
\hline \multirow[t]{2}{*}{ 6. Investigators employed weight-drop methods to induce brain trauma } & $\begin{array}{l}\text { 7. Involved non-impact (e.g. cortical ablation) or penetrating TBI. } \\
\text { (e.g. missile-induced TBI) }\end{array}$ \\
\hline & 8. Duplicate publications \\
\hline
\end{tabular}

group. The possible publication bias was assessed using funnel plots and Egger's tests. [18]. All statistical analyses were performed using Stata software (version 12.0).

\section{Results}

\section{Study selection}

On the basis of predefined standards, we identified 187 potentially relevant articles. After removing duplicate articles, 95 articles remained. Through screening titles and abstracts, 68 were excluded because they were not published in peer-reviewed journals, TCMCR was not administered orally, or traditional Chinese medicine injection/a single Chinese herb medicine was administered in the treatment group. After full-text evaluation of the remaining 26 articles, one article was excluded due to unobtainable data. Thus, 25 studies [7, 8, 19-41] were included for systematic review. Moreover, 14 studies $[8,19,22-29,32,34,35,38]$ were ultimately included in the meta-analysis. Figure 1 shows a flow chart of the study selection.

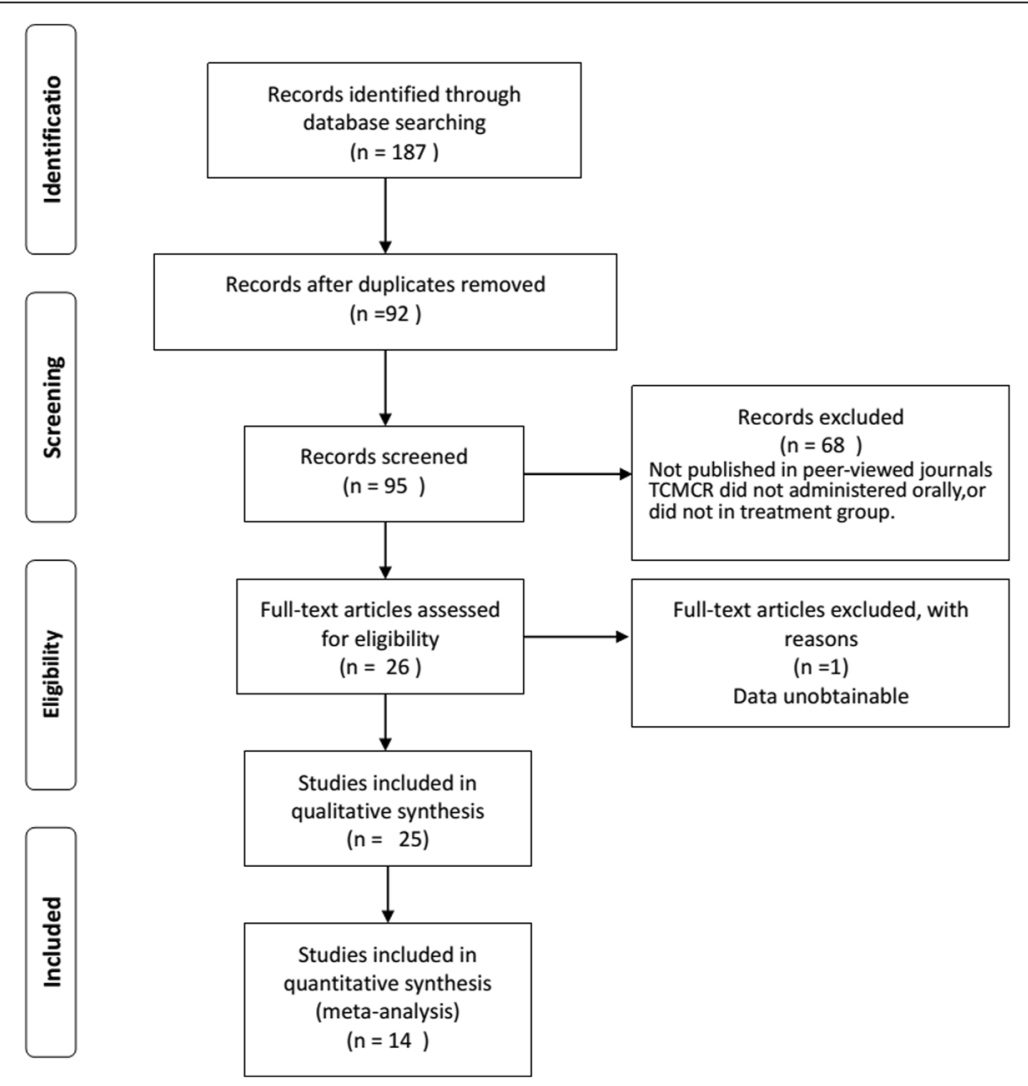

Fig. 1 PRISMA flowchart of the study selection 


\section{Study characteristics}

The 25 included studies were all conducted in China and published between 2001 and 2014. Of these, two studies [8, 41] were published in English and 23 others in Chinese. Four studies [22, 30, 34, 39] examined effects in Wistar rats, two $[27,29]$ in Kunming mice, and 19 in SD rats. The drugs administered to the treatment groups included Naozhenning granules [27], Naochuangning [27, 39], Brain injury compound decoction [37], Tongfujiannao oral liquid [23], Naoshuning [24-26, 32, 35, 38], Shenqi extraction [29], compound Huangjinxiang extraction liquid [40], Quyu Tongfu decoction [40], Angong Niuhuang pill $[21,28]$, Sanhuang Xiexin decoction [22], Brain Compound decoction [30, 34], Huayu capsules [41], modified "Shengyu" decoction [7, 8], Longxuejie capsules [19], and Jiannao Yizhi capsules [20, 31, 33, 36]. For outcome measurements, brain water content was calculated in 12 studies $[8,22-29,32,38]$, bloodbrain barrier permeability was measured in seven studies [24, 25, 27-29, 35, 38], cognitive impairment was evaluated in two trials $[37,39]$, the TNF- $\alpha$ level was detected in three studies $[8,19,29]$ and the NO level was detected in two studies $[19,34]$. The characteristics of these studies are listed in Table 3.

\section{Methodological quality of included studies}

Overall, the median quality of the 25 included studies was poor (3, interquartile range, 3-4) with scores ranging from 2 to 6 . No studies scored 0 or had a high quality rating (7-10 points). We found one study [8] with a quality score of 6 , three $[30,34,40]$ with a score of 5 , and four $[21,29,37,39]$ with a score of 4 . Animals were allocated treatment by randomization in all included articles except one [27]. Only two studies [8, 40] that were included failed to report the monitoring of physiological parameters (although the majority of these only monitored body temperature). All of the studies failed to report potential conflicts of interest, blinded outcome assessment, and blinded induction of TBI.

\section{Meta-analysis}

\section{Brain water content}

In 12 studies [8, 22-29, 32, 38], there were 25 comparisons (involving 432 animals) of brain water content after TBI, which was determined by the wet and dry weight method [42]. Pooled analysis indicated that animals in the treatment groups had significantly reduced brain water content compared to animals in the control groups $(\mathrm{SMD}=-1.421,95 \% \mathrm{CI}:-1.704$ to $-1.1379, P<0.0001)$.

There was evidence of little heterogeneity among studies $\left(\chi^{2}=39.51, \quad \mathrm{df}=24 \quad(P=0.024), I^{2}=39.2 \%\right)$, and small-study effects (Egger's test bias coefficient $=-5.8081$, $95 \%$ CI: -7.7275 to $-3.8888, P<0.001$ ). (Figs. 2 a and 3 )

\section{Integrity of blood-brain barrier}

In seven included trials [24, 25, 27-29, 35, 38], there were 12 comparisons (involving 224 animals) of bloodbrain-barrier integrity after TBI, which was analyzed by assessing extravasation of Evans blue dye [43]. The pooled analysis indicated that animals in the treatment groups had significantly better blood-brain barrier integrity than animals in the control groups $(\mathrm{SMD}=$ $-1.481 ; 95 \% \mathrm{CI}:-1.815$ to $-1.146 ; P<0.0001)$.

There was evidence of little heterogeneity among studies $\left(\chi^{2}=13.19, \quad \mathrm{df}=11 \quad(\underline{P}=0.281), \quad I^{2}=16.6 \%\right)$, and small-study effects (Egger's test bias coefficient $=$ -8.2850 , $95 \% \mathrm{CI}:-10.3545$ to $-6.21546, P<0.001)$. (Figs. 2b and 4)

\section{TNF-a levels}

In three studies $[8,19,29]$, there were seven comparisons (involving 120 animals) of TNF- $\alpha$ after TBI. The pooled analysis indicated that there was a significant difference in TNF- $\alpha$ levels between the treatment and control groups $(\mathrm{SMD}=-1.291 ; 95 \% \mathrm{CI},-1.809$ to -0.774 ; $P<0.0001)$.

There was evidence of little heterogeneity among studies $\left(\chi^{2}=9.39, \mathrm{df}=6(P=0.153), I^{2}=36.1 \%\right)$. Publication bias could not be assessed because of the small number of studies ( $<10$ studies) [44, 45]. (Fig. 5a)

\section{NO levels}

In two studies $[19,34]$, there were six comparisons (involving 108 animals) of NO after TBI. The pooled analysis indicated that there was a significant difference in NO levels between the treatment and control groups $(\mathrm{SMD}=-1.550 ; 95 \% \mathrm{CI},-1.987$ to $-1.112 ; P<0.0001)$.

There was no evidence of heterogeneity among studies $\left(\chi^{2}=1.34, \mathrm{df}=5(P=0.931), I^{2}=0 \%\right)$. Publication bias could not be assessed because of the small number of studies (<10 studies) [44, 45]. (Fig. 5b)

\section{Possible drug protection mechanism analysis}

All of the studies selected during initial screening assessed the biological mechanisms of TCMCR activity. A wide variety of possible neuroprotective mechanisms were proposed in these studies. The neuroprotective effect of TCMCR was attributed primarily to preservation of blood-brain barrier integrity, amelioration of cerebral edema, and inhibition of inflammatory response. In addition, it was found that TCMCR may regulate cerebral blood flow. (Table 4)

\section{Discussion}

To date, numerous clinical trials [46-48] that have sought new therapeutic agents for treating TBI have proven unsuccessful. However, there is increasing evidence that traditional Chinese medicine, including 
Table 3 Characteristics of included studies

\begin{tabular}{|c|c|c|c|c|c|c|}
\hline Study & Animal Species & Treatment Groups(Drug/Dose) & Anaesthetic used & Time of administration & Main Outcomes & Quality Score \\
\hline Long 2001 [1] & Mixed Kunming mice & $\begin{array}{l}\text { (1) Naozhenning Granule }(13.33 \mathrm{~g} / \mathrm{kg}) \\
\text { (2) Naochuangning }(9.08 \mathrm{~g} / \mathrm{kg}) \\
\text { (3) Naochuangning }(18.16 \mathrm{~g} / \mathrm{kg}) \\
\text { (4) Naochuangning }(36.33 \mathrm{~g} / \mathrm{kg})\end{array}$ & Unknown & $\begin{array}{l}7 \text { days before injury } \\
\text { Daily for } 10 \text { days }\end{array}$ & $\begin{array}{l}\text { Cerebral edema } \\
\text { BBB permeability }\end{array}$ & 2 \\
\hline Zhang 2002 [3] & SD rats & $\begin{array}{l}\text { (1) Brain injury compound decoction } \\
\text { (unknown) }\end{array}$ & Ether & $\begin{array}{l}3 \text { days before injury } \\
\text { Daily for } 10 \text { days }\end{array}$ & $\begin{array}{l}\text { Independent activity } \\
\text { Cognitive performance }\end{array}$ & 4 \\
\hline Wang 2003 [4] & MixedWistar rats & $\begin{array}{l}\text { (1) Naozhenning Granule }(13.13 \mathrm{~g} / \mathrm{kg}) \\
\text { (2) Naochuangning }(9.15 \mathrm{~g} / \mathrm{kg}) \\
\text { (3) Naochuangning }(19.10 \mathrm{~g} / \mathrm{kg}) \\
\text { (4) Naochuangning }(38.10 \mathrm{~g} / \mathrm{kg})\end{array}$ & Pentobarbital & $\begin{array}{l}\text { After injury } \\
\text { Daily for } 14 \text { days }\end{array}$ & $\begin{array}{l}\text { Memory performance } \\
\text { Endothelia content }\end{array}$ & 4 \\
\hline Zhang 2004 [5] & SD rats & $\begin{array}{l}\text { (1Tongfujiannao Oral Liquid(7.5 g/kg) } \\
\text { (2Tongfujiannao Oral Liquid(3.125 g/kg) }\end{array}$ & Unknown & $\begin{array}{l}\text { After injury } \\
\text { Daily for } 3 \text { days }\end{array}$ & $\begin{array}{l}\text { Brain water content MDAISOD } \\
\text { content(Brain) \LPS content(Plasma) } \\
\text { Histopathological }\end{array}$ & 3 \\
\hline Cui 2005a [6] & Male SD rats & (1)Naoshuning $(15 \mathrm{~g} / \mathrm{kg})$ & chloralhydrate & $\begin{array}{l}3 \text { days before injury } \\
\text { Twice for } 4 \text { days }\end{array}$ & $\begin{array}{l}\text { Neurological function } \\
\text { HistopathologicalBrain water conte }\end{array}$ & 3 \\
\hline Cui 2005b [7] & MaleSD rats & (1)Naoshuning $(15 \mathrm{~g} / \mathrm{kg})$ & chloralhydrate & $\begin{array}{l}3 \text { days before injury } \\
\text { Twice for } 4 \text { days }\end{array}$ & $\begin{array}{l}\text { BBB permeabilityBrain water content } \\
\text { MMP-9 }\end{array}$ & 3 \\
\hline Yu 2005 [8] & Kunmingmice & $\begin{array}{l}\text { (1) Shenqi Extraction }(0.28 \mathrm{~g} / \mathrm{kg}) \\
\text { (2) Shenqi Extraction }(0.14 \mathrm{~g} / \mathrm{kg}) \\
\text { (3)Shenqi Extraction }(0.07 \mathrm{~g} / \mathrm{kg})\end{array}$ & Ether & $\begin{array}{l}3 \text { days before injury } \\
\text { Daily for } 3 \text { days }\end{array}$ & $\begin{array}{l}\text { BBB permeability } \\
\text { Brain water content } \\
\text { TNF-a(Brain)\ } \backslash \text { T content(Serum) }\end{array}$ & 4 \\
\hline Zhou 2007 [9] & MixedSD rats & $\begin{array}{l}\text { (1) Huayu capsule }(1.030 \mathrm{~g} / \mathrm{kg}) \\
\text { (2) Huayu capsule }(0.515 \mathrm{~g} / \mathrm{kg}) \\
\text { (3) Huayu capsule }(0.258 \mathrm{~g} / \mathrm{kg})\end{array}$ & chloralhydrate & $\begin{array}{l}\text { After injury } \\
\text { Daily for } 7 \text { days }\end{array}$ & $\begin{array}{l}\text { (1) Nerve-muscle catching capability. } \\
\text { (2) Histopathological }\end{array}$ & 3 \\
\hline Cui 2008a [10] & MaleSD rats & (1)Naoshuning $(7.5 \mathrm{~g} / \mathrm{kg})$ & chloralhydrate & $\begin{array}{l}3 \text { days before injury } \\
\text { Twice for } 4 \text { days }\end{array}$ & $\begin{array}{l}\text { Brain water content } \\
\text { BBB permeabilityAQP-4 content }\end{array}$ & 3 \\
\hline Cui 2008b [11] & MaleSD rats & (1)Naoshuning $(7.5 \mathrm{~g} / \mathrm{kg})$ & Unknown & $\begin{array}{l}3 \text { days before injury } \\
\text { Twice for } 4 \text { days }\end{array}$ & $\begin{array}{l}\text { BBB permeability } \\
\text { Histopathological cerebral } \\
\text { microvascular density }\end{array}$ & 3 \\
\hline Miao 2008 [12] & MaleWistar rats & (1)Brain Compound decoction $(10 \mathrm{~g} / \mathrm{kg})$ & Pentobarbital & $\begin{array}{l}\text { Immediately after injury } \\
\text { Twice for } 7 \text { days }\end{array}$ & $\mathrm{Na}^{+}-\mathrm{K}^{+}-\mathrm{ATPCa}^{2+}-\mathrm{ATP}$ & 5 \\
\hline Cui 2009a [13] & SD rats & (1)Naoshuning $(7.5 \mathrm{~g} / \mathrm{kg})$ & Unknown & $\begin{array}{l}3 \text { days before injury } \\
\text { Daily for } 3 \text { days }\end{array}$ & $\begin{array}{l}\text { Histopathological (HE statin) } \\
\text { Edema volume } \\
\text { Brain water content }\end{array}$ & 3 \\
\hline Cui 2009b [14] & MaleSD rats & (1)Naoshuning $(7.5 \mathrm{~g} / \mathrm{kg})$ & Unknown & $\begin{array}{l}3 \text { days before injury } \\
\text { Twice for } 8 \text { days }\end{array}$ & $\begin{array}{l}\text { MMP-2/9 content } \\
\text { Brain water content } \\
\text { EB content }\end{array}$ & 3 \\
\hline Xiong 2009 [15] & SD rats & $\begin{array}{l}\text { (1) Quyu Tongfu decoction }(10 \mathrm{ml} / \mathrm{kg}) \\
\text { (2) compound Huangjinxiang extraction } \\
\text { liquid(10 ml/kg) }\end{array}$ & Pentobarbital & $\begin{array}{l}20 \text { min after injury } \\
\text { Daily for } 24 \mathrm{~h}\end{array}$ & AQP- 4 content & 5 \\
\hline Xie 2010 [16] & MixedSD rats & (1) Angong Niuhuang Pill $(0.6 \mathrm{~g} / \mathrm{kg})$ & chloralhydrate & $\begin{array}{l}12 \mathrm{~h} \text { before injury } \\
\text { Twice for } 60 \mathrm{~h}\end{array}$ & $\begin{array}{l}\text { Synaptic density } \\
\text { BBB permeability } \\
\text { Cerebral edema }\end{array}$ & 3 \\
\hline
\end{tabular}


Table 3 Characteristics of included studies (Continued)

\begin{tabular}{|c|c|c|c|c|c|c|}
\hline Xu 2010 [17] & $\begin{array}{l}\text { Mixed } \\
\text { SD rats }\end{array}$ & (1)Angong Niuhuang Pill (0.121 g/2 ml) & Pentobarbital & $\begin{array}{l}\text { After injury } \\
\text { Daily for } 12 \text { days }\end{array}$ & $\begin{array}{l}\text { ApoE content } \\
\text { (Brain and CSF) }\end{array}$ & 4 \\
\hline Miao 2011 [18] & $\begin{array}{l}\text { Male } \\
\text { Wistar rats }\end{array}$ & (1)Brain Compound decoction $(10 \mathrm{~g} / \mathrm{kg})$ & Pentobarbital & $\begin{array}{l}\text { Immediately after injury } \\
\text { Twice for } 7 \text { days }\end{array}$ & $\begin{array}{l}\text { NOInNOS(Brain) } \\
\text { Brain water content } \\
\text { Histopathological }\end{array}$ & 5 \\
\hline Zhang 2011 [19] & Wistar rats & (1)Sanhuang Xiexin Decoction $(10 \mathrm{~g} / \mathrm{kg})$ & chloralhydrate & $\begin{array}{l}\text { Immediately after injury } \\
\text { Daily for } 72 \mathrm{~h}\end{array}$ & NF-KB\IL- 6 content & 3 \\
\hline Wang 2012a [20] & SD rats & (1)Longxuejie capsule $(2.6$ mg/g/d) & Unknown & $\begin{array}{l}\text { after injury } \\
\text { Daily for } 5 d\end{array}$ & NOITNF-a content (serum) & 3 \\
\hline Wang 2012b [21] & $\begin{array}{l}\text { Male } \\
\text { SD rats }\end{array}$ & $\begin{array}{l}\text { (1)modified "Shengyu"decoction } \\
4.0 \mathrm{~mL} / 200 \mathrm{~g} / \mathrm{d}\end{array}$ & Unknown & $\begin{array}{l}6 \mathrm{~h} \text { after injury } \\
\text { Twice for } 72 \mathrm{~h}\end{array}$ & $\begin{array}{l}\text { Histopathological caspase-3 } \\
\text { activity }\end{array}$ & 3 \\
\hline Zhao 2012 [22] & $\begin{array}{l}\text { Mixed } \\
\text { SD rats }\end{array}$ & (1)JiannaoYizhi capsules $(6.0 \mathrm{~g} / \mathrm{kg} / \mathrm{d})$ & chloral hydrate & $\begin{array}{l}24 \mathrm{~h} \text { after injury } \\
\text { Daily for } 10 \mathrm{~d}\end{array}$ & CGRP content (Plasma) & 3 \\
\hline Zhou 2012 [23] & SD rats & (1)JiannaoYizhi capsules $(6.0 \mathrm{~g} / \mathrm{kg} / \mathrm{d})$ & chloral hydrate & $\begin{array}{l}24 \mathrm{~h} \text { after injury } \\
\text { Daily for } 10 \mathrm{~d}\end{array}$ & NPY content (serum) & 3 \\
\hline Fan 2013a [24] & SD rats & (1)JiannaoYizhi capsules $(6.0 \mathrm{~g} / \mathrm{kg} / \mathrm{d})$ & chloral hydrate & $\begin{array}{l}24 \mathrm{~h} \text { after injury } \\
\text { Daily for } 10 \mathrm{~d}\end{array}$ & S100B content (serum) & 3 \\
\hline Fan 2013b [25] & SD rats & (1)JiannaoYizhi capsules $(6.0 \mathrm{~g} / \mathrm{kg} / \mathrm{d})$ & chloral hydrate & $\begin{array}{l}24 \mathrm{~h} \text { after injury } \\
\text { Daily for } 10 \mathrm{~d}\end{array}$ & NSE content (serum) & 3 \\
\hline Zhao 2014 [26] & $\begin{array}{l}\text { Male } \\
\text { SD rats }\end{array}$ & $\begin{array}{l}\text { (1) modified "Shengyu"decoction } 0.5 \mathrm{~mL} / 200 \mathrm{~g} \\
\text { (2)modified "Shengyu"decoction } 1.0 \mathrm{~mL} / 200 \mathrm{~g} \\
\text { (3) modified "Shengyu"decoction } 2.0 \mathrm{~mL} / 200 \mathrm{~g}\end{array}$ & chloral hydrate & $\begin{array}{l}6 \mathrm{~h} \text { after injury } \\
\text { Daily for } 7 \mathrm{~d}\end{array}$ & 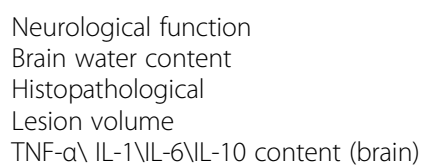 & 6 \\
\hline
\end{tabular}

Note: BBB Blood-brain-barrier, MMP-9 matrix metalloprotein 9, TNF- $a$ tumor necrosis factor-a, LL-1 interleukin-1, IL-6 interleukin-6, IL-10 interleukin-10, NSE 2-phospho-D-glycerate hydrolase, NPY Neuropeptide Y, CGRP Calcitonin Gene Related Peptide, SOD superoxidedismutase, MDA malondialdehyde, NO Nitrogen monoxide, SD Sprague Dawley.- 

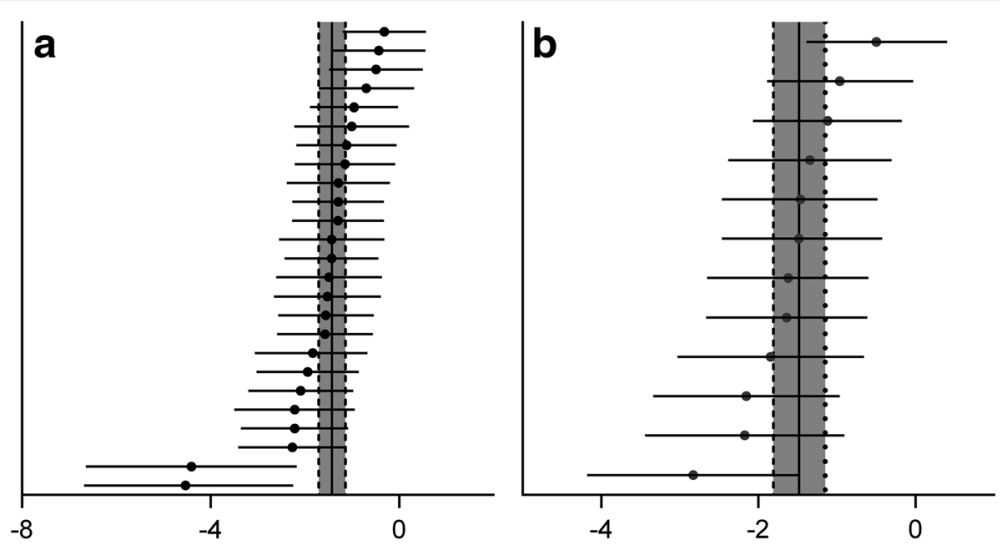

Fig. 2 Meta-analysis of effect of TCMCR on brain water content reduction (a) and integrity of BBB improvement (b). The horizontal lines represent the mean estimated effect size and the $95 \%$ confidence intervals(Cl) for each individual comparison according to their effect on brain water content (a) and integrity of BBB (b). The SMD and the $95 \% \mathrm{Cl}$ of the global estimate are represented as solid and dashed vertical lines, respectively

TCMCR, extracts, and acupuncture, have clinical benefit in the treatment of TBI patients [49-51]. Because TCMCR is the main form of TCM drug treatment, robust evidence of its effects on TBI must be provided. Therefore, we have conducted the first systematic review and meta-analysis of the effects of TCMCR in animal models of TBI. Because systematic review and metaanalysis of animal experiments could provide strong evidence in an unbiased manner. Although small-study effects and statistical heterogeneity among studies were present, our results indicated that TCMCR potentially exerts neuroprotective effects in terms of reduction of brain water content, amelioration of BBB permeability, and deduction of TNF- $\alpha / \mathrm{NO}$ after TBI. Similar work [52] was performed in the context of experimental stroke that demonstrated the neuroprotective effects of
Buyang Huanwu decoction, a well-known TCMCR, on animal stroke models. Though they are different diseases, many aspects of their respective pathologies are similar, and these investigations provide further evidence of the neuroprotective efficacy of TCMCR, supporting its potential use for human TBI therapy.

Concerning study quality, we found that the methodological quality of most included studies was generally poor, as many failed to report blinded outcome assessment, blinded induction of TBI, sample size calculation, compliance with animal welfare regulations, and potential conflicts of interest. However, because we sought to report on overall quality, we did not arbitrarily exclude them solely on the basis of these defects [53].

The current study has some limitations that have also been observed in previous studies [18, 54, 55]. First,

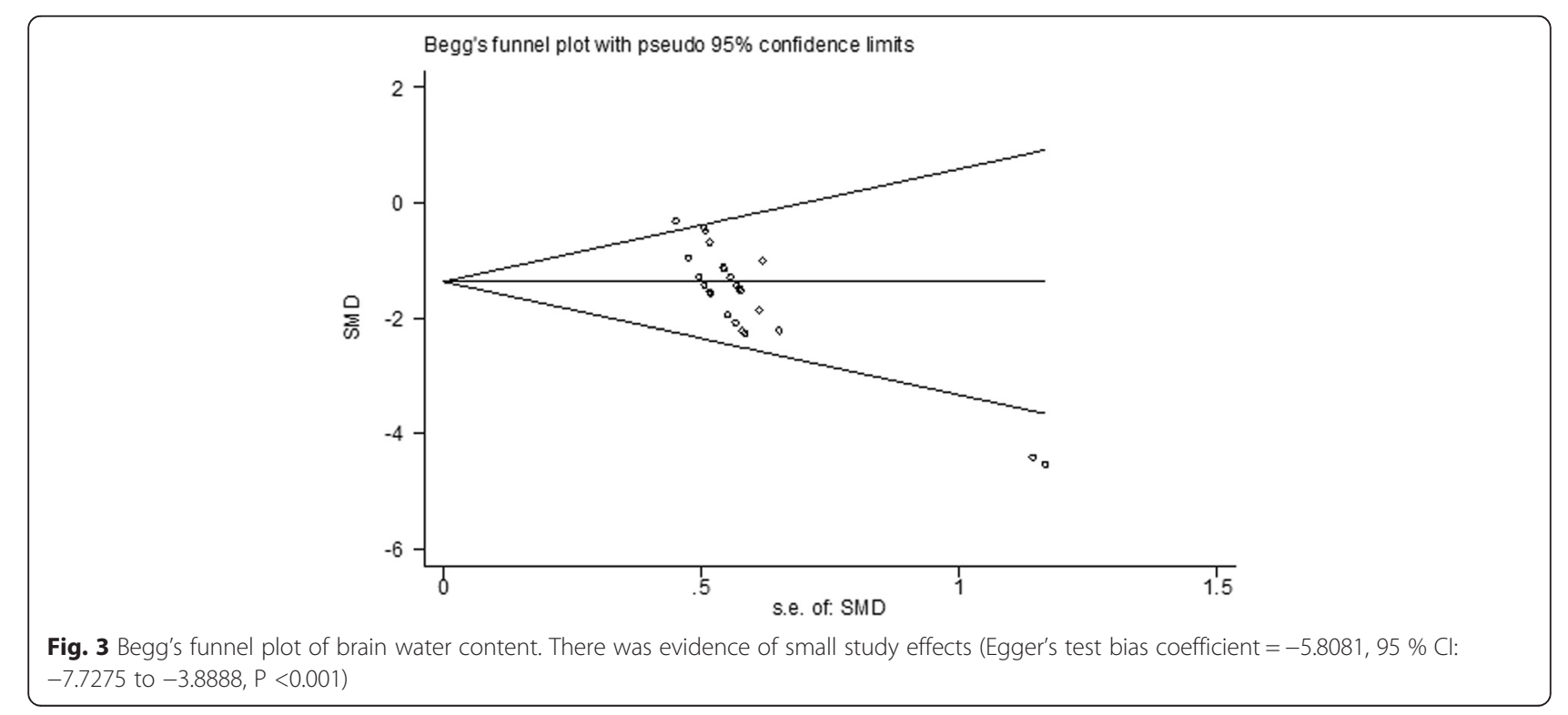




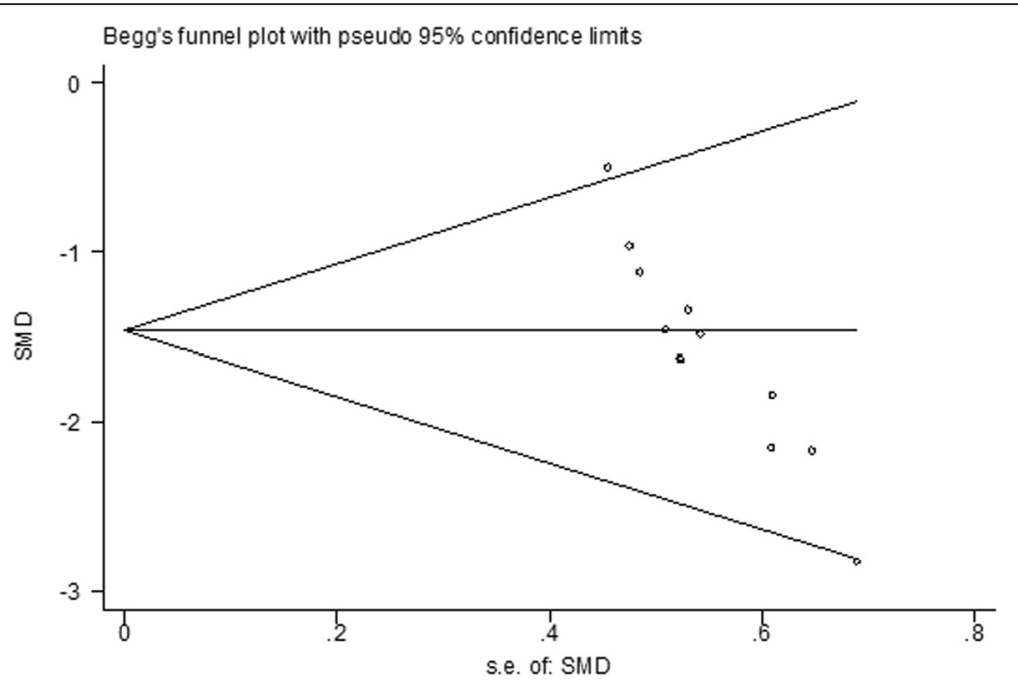

Fig. 4 Begg's funnel plot of integrity of BBB. There was evidence of small study effects (Egger's test bias coefficient $=-8.2850,95 \%$ Cl: -10.3545 to $-6.21546, P<0.001$ )

although we made an effort to identify all relevant studies, our analysis could only be based on articles published in English or Chinese and did not take the unpublished data and the relevant articles published in other languages into account. Moreover, most of them published in local journal particularly, some publications were showed in journal from university. So there was evidence of small-study effects and publication bias should be considered. Second, no studies specifying the degree of severity (e.g., mild, moderate, or severe). The results of different studies could have been more accurately compared if injury severity had been reported consistently. Third, as in previous studies [56-58], the methodological quality of the included studies was generally poor. Due to the poor quality of the studies, the results of this review are likely to be influenced by many factors. Of course, it should be noted that negative judgment did not necessarily indicate that the experiment itself was performed inadequately; it indicated that there was inadequate information for assessing its quality. Fourth, although the findings indicate that TCMCR treatment benefits can be found in the TBI model with weight-drop mothed. For the weight-drop model, this model is limited in the production of primary lesions that are macroscopically meaningful once it is not capable of creating cranial fractures with levels of energy compatible with life after impact. It presented discrete focal lesions in a small number of animals and only at elevated levels of energy, but in accordance with what was described in similar studies [59]. Moreover, any single animal model may not be able to fully mimic the highly heterogeneous nature of human TBI [60]. Lastly,

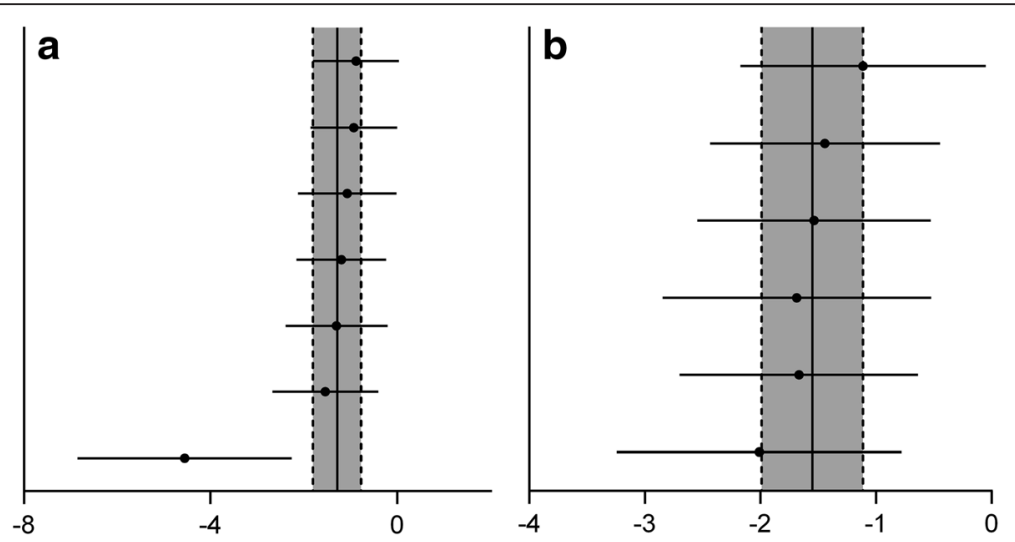

Fig. 5 Meta-analysis of effect of TCMCR on the reduction of TNF-a(a) and $\mathrm{NO}(\mathbf{b})$. The horizontal lines represent the mean estimated effect size and the $95 \%$ confidence intervals(Cl) for each individual comparison according to their effect on TNF- $\mathrm{a}(\mathbf{a})$ and $\mathrm{NO}$ (b). The SMD and the $95 \% \mathrm{Cl}$ of the global estimate are represented as solid and dashed vertical lines, respectively 
Table 4 Possible protective mechanisms of TCMCR

\begin{tabular}{|c|c|}
\hline Possible drug protective mechanisms & Studies \\
\hline $\begin{array}{l}\text { Increase in cerebral microvascular } \\
\text { patency and integrity }\end{array}$ & {$[11]$} \\
\hline Improve cognitive deficits & {$[3,4]$} \\
\hline Ameliorated cerebral edema & {$[1,5-8,10,13-16,19,26]$} \\
\hline $\begin{array}{l}\text { Attenuated disruption of the } \\
\text { blood-brain-barrier }\end{array}$ & {$[1,7,8,10,11,14,16,24,25]$} \\
\hline Reduced the neuronal apoptosis & {$[9,21]$} \\
\hline Suppressed oxidative stress & {$[5,18,20]$} \\
\hline Regulation of cerebral blood flow & {$[4,8,22,23]$} \\
\hline $\begin{array}{l}\text { Increase activities of } \mathrm{Na}^{+}-\mathrm{K}^{+}-\mathrm{ATPase} \\
\mathrm{Ca}^{2+} \text {-ATPase and regulation of } \mathrm{Ca}^{2+}\end{array}$ & {$[12]$} \\
\hline $\begin{array}{l}\text { promote the synthesizing and secreting } \\
\text { of apolipoprotein } E\end{array}$ & {$[17]$} \\
\hline Inhibited the inflammatory response & {$[5,8,19,20,26]$} \\
\hline
\end{tabular}

we limited our analysis to the alternation of $\mathrm{BBB}$ integrity, brain water content, and TNF- $\alpha / \mathrm{NO}$ levels following TBI, largely due to insufficient data regarding histopathology, such as lesion volume and neurobehavioral outcomes such as cognitive performance and motor function.

Additionally, heterogeneity must be considered for any meta-analysis. The main reasons for heterogeneity were the limited number of trials and small cohorts [61]; therefore, additional large-scale clinical trials are required. Another important reason for the existence of heterogeneity was the low quality and potential bias of the trials selected for analysis. The surprisingly low heterogeneity of NO levels in the meta-analysis requires further consideration. It is also associated with the poor methodological quality of the selected trials, which require additional investigation.

To improve the clinical translation, our recommendations for the conduct of future animal studies of TCMCR or other TCM drugs are as follows: (1) More studies have shown that TCMCR is a whole greater than the sum of its parts in terms of its composition and pharmacodynamic action. In order to make full use of the advantages offered by TCMCR, it is essential to address the difficulties in studying TCMCR, including the role played by the material basis and physical basis in TCM's therapeutic effects, and the rules of compatibility, pharmacology, and action mechanism of TCMCR [62]; (2) Other TBI models are needed to investigate the effects of TCM/TCMCR on TBI; (3) Further researchers are strongly recommended to consult and follow the ARRIVE (Animal Research: Reporting In Vivo Experiments) guidelines to report their animal experimental results [63, 64]; (4) Other long-term neuropsychological outcomes should also be focused on, such as the cognitive performance, the motor function.

\section{Conclusions}

Despite limitations, the animal data has shown that TCMCR may be neuroprotective in the TBI model with weight-drop mothed. However, successful clinical translation of this neuroprotective strategy necessitates rigorous, robust, and detailed pre-clinical evaluation. Therefore, additional well-designed and well-reported experimental animal studies are needed.

\section{Competing interests \\ The authors declare that they have no competing interests.}

\section{Authors' contributions}

W.P. and B. Y. conceived of the study, and participated in its design and coordination and drafted the manuscript; Z.W., Y.W., and C. S. carried out the literature search, study selection and helped to draft the manuscript; J.Z. and X. X. participated in the data extraction, performed the statistical analysis, and helped to draft the manuscript. All authors read and approved the final manuscript.

\section{Acknowledgments}

This work was financially supported by the National Natural Science Foundation of China (NO. 81303074).

\section{Author details}

${ }^{1}$ Institute of Integrated Medicine, Xiangya Hospital, Central South University, Changsha 410008, China. ${ }^{2}$ Department of Integrated Chinese and Western Medicine, The Second Xiangya Hospital, Central South University, No.139 Middle Renmin Road, Changsha, Hunan 410011, P.R. China.

Received: 3 September 2015 Accepted: 3 March 2016

Published online: 09 March 2016

\section{References}

1. Feigin VL, Theadom A, Barker-Collo S, Starkey NJ, McPherson K, Kahan M, Dowell A, Brown P, Parag V, Kydd R, et al. Incidence of traumatic brain injury in New Zealand: a population-based study. Lancet Neurol. 2013;12(1): 53-64.

2. Janowitz T, Menon DK. Exploring new routes for neuroprotective drug development in traumatic brain injury. Sci Transl Med. 2010;2(27):27rv21.

3. Margulies S, Hicks R, Combination Therapies for Traumatic Brain Injury Workshop L. Combination therapies for traumatic brain injury: prospective considerations. J Neurotrauma. 2009;26(6):925-39.

4. Kabadi SV, Faden AI. Neuroprotective strategies for traumatic brain injury: improving clinical translation. Int J Mol Sci. 2014;15(1):1216-36.

5. Frantz S. Drug discovery: playing dirty. Nature. 2005;437(7061):942-3.

6. Zhong YQ, Fu JJ, Liu XM, Diao X, Mao B, Fan T, Yang HM, Liu GJ, Zhang WB. The reporting quality, scientific rigor, and ethics of randomized placebocontrolled trials of traditional Chinese medicine compound formulations and the differences between Chinese and non-Chinese trials. Curr Ther Res Clin Exp. 2010;71(1):30-49.

7. Wang Y, Li Y, Xi X, Ma D. Effect of modified"Shengyu" decoction on the apoptosis of neural cells after traumatic brain injury in rats. Med J Commun. 2012;26(4):312-5.

8. Zhao GW, Wang Y, Li YC, Jiang ZL, Sun L, Xi X, He P, Wang GH, Xu SH, Ma $\mathrm{DM}$, et al. The neuroprotective effect of modified "Shengyu" decoction is mediated through an anti-inflammatory mechanism in the rat after traumatic brain injury. J Ethnopharmacol. 2014;151(1):694-703.

9. Sun M, Zhang JJ, Shan JZ, Zhang H, Jin CY, Xu S, Wang YL. Clinical observation of Danhong Injection (herbal TCM product from Radix Salviae miltiorrhizae and Flos Carthami tinctorii) in the treatment of traumatic intracranial hematoma. Phytomedicine. 2009;16(8):683-9.

10. Jin X, Shen G, Gao F, Zheng X, Xu X, Shen F, Li G, Gong J, Wen L, Yang X, et al. Traditional Chinese drug ShuXueTong facilitates angiogenesis during wound healing following traumatic brain injury. J Ethnopharmacol. 2008; 117(3):473-7.

11. Bai Y, Yao HX, Hu ML, Wang LR, Jin LD, Wang WT, Lin LN. Effects of shenmai injection on pulmonary aquaporin 1 in rats following traumatic brain injury. Chin Med J (Engl). 2011;124(3):457-60. 
12. Macleod MR, O'Collins T, Howells DW, Donnan GA. Pooling of animal experimental data reveals influence of study design and publication bias. Stroke. 2004;35(5):1203-8.

13. Garcia-Bonilla L, Campos M, Giralt D, Salat D, Chacon P, HernandezGuillamon M, Rosell A, Montaner J. Evidence for the efficacy of statins in animal stroke models: a meta-analysis. J Neurochem. 2012;122(2):233-43.

14. Peng W, Xing Z, Yang J, Wang Y, Wang W, Huang W. The efficacy of erythropoietin in treating experimental traumatic brain injury: a systematic review of controlled trials in animal models. J Neurosurg. 2014;121(3):653-64.

15. Egger M, Davey Smith G, Schneider M, Minder C. Bias in meta-analysis detected by a simple, graphical test. BMJ. 1997;315(7109):629-34.

16. Sacks HS, Berrier J, Reitman D, Ancona-Berk VA, Chalmers TC. Meta-analyses of randomized controlled trials. N Engl J Med. 1987;316(8):450-5.

17. Higgins J, Green S. Cochrane Handbook for Systematic Reviews of Interventions version 5.1.0 (updated March 2011). Cochrane Collaboration. 2011 [Epub ahead of print].

18. Ker K, Perel $P$, Blackhall K. Beta-2 receptor antagonists for traumatic brain injury: a systematic review of controlled trials in animal models. CNS Neurosci Ther. 2009;15(1):52-64.

19. Wang $M$, Li J. Effects of Longxuejie capsule on nitric oxide and tumor necrosis factor-a in serum of rats with craniocerebral injury. Modern J Integrated Traditional Chinese and Western Medicine. 2012;21(12):1279-80.

20. Zhou Z, Fan X, Zhao X, Hou W, Zhang Y, Bai L, Fang Y. Effect of Jiannao Yizhi capsules on blood neuropeptide $Y$ in model rats with traumatic brain injury. Modern J Integrated Chinese Traditional and Western Medicine. 2012; 21(31):3437-9.

21. Xu Z, Huang L, Dai Y, Wang Y. Effects of Angongniuhuang Pill on the Synthesis of ApolipoproteinE in Brains of Rats after Traumatic Brain Injury. J Zhejiang University of Traditional Chinese Medicine. 2010;34(4):487-8.

22. Zhang G, Ling J, Yan M, Wang D. Effect of Sanhuang Xiexin Decoction on Expression of Cerebral Nuclear -kB and Interleukin-6 in Rats after Severe Traumatic Brain Injury. J New Chinese Medicine. 2011;43(5):135-7.

23. Zhang Q, Wang Y, Cheng H, Zhang C, Wang J. Experimental Study on Effect of Tongfujiannao Oral Liquid for Rats with Craniocerebral Trauma. J Emergency in Traditional Chinese Medicine. 2004;13(5):309-10.

24. Cui $X$, Yin L, Wang Y-I. Effects of Naoshuning on permeability of blood-brain barrier and MMP-9 expression in TBI rats. J Beijing University of Traditional Chinese Medicine. 2005;28(2):60-2.

25. Cui X, Yin L, Wang Y, Zhang X, Zhang M. Effects of Naoshuning on brain water content and the protein expression of AQP4 in rats with traumatic brain injury. J Beijing University of Traditional Chinese Medicine. 2008;31(7):474-7.

26. Cui X, Liu M, Zhao J, Wang Y-I, Zhao Y. Dynamic observation on interventional effect of Naoshuning on traumatic brain edema in rats by using MRI. J Beijing University of Traditional Chinese Medicine. 2009;32(11): 747-50.

27. Long Z, Wang T, Wang X, Xia K, Wang Z. Effect of Naochuangning on cerebral edema and permeability of blood-brain barrier. J Anhui Traditional Chinese Medical College. 2001;20(2):41-3.

28. Xie Y, Zhu W. Effects of Angongniuhuang Pill on cerebral edema and permeability of blood-brain barrier in rats after traumatic brain injury. International Medicine and Health Guidance News 2010, 16(17). [Epub ahead of print]

29. Yu H, Wang Q, Zhou S. Effect of Shenqi extraction on closed craniocerebral injury in mice. Chinese J Veterinary Drug. 2005;39(3):16-8.

30. Miao K, Wu X, Chen Q, Zhang X. Effect of compound decotion on activities of $\mathrm{Na}+-\mathrm{K}+$-ATPase $、 \mathrm{Ca} 2+-$ ATPase and regulation of $\mathrm{Ca} 2+$ after traumatic brain injury. Chinese J Trauma. 2008;24(12):1002-6.

31. Fan X, Bai L, Zhao X, Zhang Y, Zhou Z-g, Chang T. Effect of Jiannao Yizhi Capsules on Blood S100B in Modle Rats with Traumatic Brain Injury. Chinese J Traditional Medical Science and Technology. 2013;20(1):23-4.

32. Cui $X$, Yin L, Wang Y. Effects of Naoshuning on neurological outcome following traumatic brain injury in rats. Chinese J Rehabilitation Theory and Practice. 2005;11(1):21-2

33. Zhao X, Fan X, Hou W, Zhang Y, Zhou Z-g, Bai L-n, Fang Y. Effect of Jiannao Yizhi capsules on plasma levels of calcitonin gene-related peptide in rats with traumatic brain injury. Chinese J Integrated Traditional and Western Medicine in Intensive and Critical Care. 2012;19(5):290-2.

34. Miao J, Chen Q, Wu X, Liu Z, Zhang X. Effects of compound decotion on activity and expression of nitric oxide and neuronal nitric oxide synthase in the brain of traumatic brain injury rat model. Chinese J Clinical Pharmacology and Therapeutics. 2011;16(11):1340-6.
35. Cui X, Yin L, Wang Y, Zhang X, Zhang M, Chen H, Liu F. Experimental Study on Protective Role of Naoshuning on Micro-Cerebral Blood Vessels in BrainInjured Rats. Chinese J Basic Medicine In Traditional Chinese Medicine. 2008; 14(3):188-190+240.

36. Fan X, Zhao X, Zhou Z-g, Zhang Y, Chang T, Bai L, Hou W, Fang Y, Zhou F. Effect of Jiannao Yizhi Capsules on Blood NSE in Modle Rats with Traumatic Brain Injury. Chinese Archives of Traditional Chinese Medicine. 2013;31(5): 1066-8.

37. Zhang J, Wang Z, Liu G, Lou J, Liu G, Zhu S. Brain injury compound decoction ameliorates traumatic brain injury-induced cognitive impairment in rats. China J Traditional Chinese Medicine and Pharmacy. 2002;17(4):251-2.

38. Cui $X$, Yin L, Wang Y, Zhang $X$, Zhang M, Zhao Y, Liu Z, Ju L. Effect of Naoshuning on MMP-2/9 protein expression in traumatic brain injury rats. China J Traditional Chinese Medicine and Pharmacy. 2009;24(2):211-3.

39. Wang T, Long Z, Bai M. Effect of Naochuangning on Memory and Endothelin Content in Rats with Open Cerebral Laceration. China J Experimental Traditional Medical Formulae. 2003;9(1):35-6.

40. Xiong G, Zhang D, Xiong L, Chai X, Bi C, Fan X. Effect of compound Huangjinxiang extraction liquid on auuaporin 4 expression after experimental traumatic brain injury in rats. Central South Pharmacy. 2009;7(3):165-7.

41. Zhou C, Zhang J, Wang Y, Qian H, Gong L, Huang G. Huayu capsule enhances limb-catching capability of rats with experimental open traumatic brain injury*. Neural Regeneration Research. 2007;2(4):221-4.

42. Bareyre F, Wahl F, McIntosh TK, Stutzmann JM. Time course of cerebral edema after traumatic brain injury in rats: effects of riluzole and mannitol. J Neurotrauma. 1997;14(11):839-49.

43. Aoki T, Sumii T, Mori T, Wang X, Lo EH. Blood-brain barrier disruption and matrix metalloproteinase-9 expression during reperfusion injury: mechanical versus embolic focal ischemia in spontaneously hypertensive rats. Stroke. 2002:33(11):2711-7.

44. Sterne JA, Gavaghan D, Egger M. Publication and related bias in metaanalysis: power of statistical tests and prevalence in the literature. J Clin Epidemiol. 2000;53(11):1119-29.

45. Singh B, Parsaik AK, Prokop LJ, Mittal MK. Endovascular therapy for acute ischemic stroke: a systematic review and meta-analysis. Mayo Clinic Proceedings Mayo Clinic. 2013;88(10):1056-65.

46. Skolnick BE, Maas Al, Narayan RK, van der Hoop RG, MacAllister T, Ward JD, Nelson NR, Stocchetti N, Investigators ST. A clinical trial of progesterone for severe traumatic brain injury. N Engl J Med. 2014;371(26):2467-76.

47. Robertson CS, Hannay HJ, Yamal JM, Gopinath S, Goodman JC, Tilley BC, Epo Severe TBITI, Baldwin A, Rivera Lara L, Saucedo-Crespo H, et al. Effect of erythropoietin and transfusion threshold on neurological recovery after traumatic brain injury: a randomized clinical trial. JAMA. 2014;312(1):36-47.

48. Ripley DL, Morey CE, Gerber D, Harrison-Felix C, Brenner LA, Pretz CR, Cusick C, Wesnes K. Atomoxetine for attention deficits following traumatic brain injury: results from a randomized controlled trial. Brain Inj. 2014;28(12):1514-22.

49. Zhao W, Wang C, Li Z, Chen L, Li J, Cui W, Ding S, Xi Q, Wang F, Jia F, et al. Efficacy and safety of transcutaneous electrical acupoint stimulation to treat muscle spasticity following brain injury: a double-blinded, multicenter randomized controlled trial. PLoS One. 2015;10(2):e0116976.

50. Saito S, Kobayashi T, Osawa T, Kato S. Effectiveness of Japanese herbal medicine yokukansan for alleviating psychiatric symptoms after traumatic brain injury. Psychogeriatrics. 2010;10(1):45-8.

51. Gu J, Zhang X, Fei Z, Wen A, Qin S, Yi S, Chen Y, Li X. [Rhubarb extracts in treating complications of severe cerebral injury]. Chin Med J (Engl). 2000; 113(6):529-31.

52. Wei RL, Teng HJ, Yin B, Xu Y, Du Y, He FP, Chu KT, Luo BY, Zheng GQ. A systematic review and meta-analysis of buyang huanwu decoction in animal model of focal cerebral ischemia. Evid Based Complement Alternat Med. 2013:2013:138484.

53. Wardlaw JM, Warlow CP, Sandercock PA, Dennis MS, Lindley RI. Neuroprotection disappointment yet aGAIN. Lancet. 2000:356(9229):597.

54. Perel P, Roberts I, Sena E, Wheble P, Briscoe C, Sandercock P, Macleod M, Mignini LE, Jayaram $P$, Khan KS. Comparison of treatment effects between animal experiments and clinical trials: systematic review. BMJ. 2007; 334(7586):197.

55. Wheaton P, Mathias JL, Vink R. Impact of pharmacological treatments on outcome in adult rodents after traumatic brain injury: a meta-analysis. J Psychopharmacol. 2011;25(12):1581-99.

56. Junhua Z, Menniti-Ippolito F, Xiumei G, Firenzuoli F, Boli Z, Massari M, Hongcai S, Yuhong H, Ferrelli R, Limin H, et al. Complex traditional Chinese 
medicine for poststroke motor dysfunction: a systematic review. Stroke. 2009;40(8):2797-804.

57. Sheng C, Peng W, Xia Z-a, Wang Y, Chen Z, Su N, Wang Z. The impact of ginsenosides on cognitive deficits in experimental animal studies of Alzheimer's disease: a systematic review. BMC Complement Altern Med 2015, 15(1). [Epub ahead of print]

58. Tao W, Luo X, Cui B, Liang D, Wang C, Duan Y, Li X, Zhou S, Zhao M, Li Y, et al. Practice of traditional chinese medicine for psycho-behavioral intervention improves quality of life in cancer patients: A systematic review and meta-analysis. Oncotarget. 2015 [Epub ahead of print].

59. Silva Ddos S, Brito JN, Ibiapina JO, Lima MF, Medeiros AR, Queiroz BH, Guedes VO. Traumatic brain injury: clinical and pathological parameters in an experimental weightdrop model. Acta Cir Bras. 2011;26(2):94-100.

60. Xiong Y, Mahmood A, Chopp M. Animal models of traumatic brain injury. Nat Rev Neurosci. 2013;14(2):128-42.

61. Peng $W$, Yang J, Yang B, Wang L, Xiong XG, Liang Q. Impact of statins on cognitive deficits in adult male rodents after traumatic brain injury: a systematic review. Biomed Res Int. 2014;2014:261409.

62. Sheng-shan D, Run-hui L, Peng J, Lei L, Chuan Z, Guo-an L, Wei-dong Z. System biology and its application in compound recipe of traditional Chinese medicine study. World Science and Technology. 2008;10(2):116-21.

63. Danos O, Davies K, Lehn P, Mulligan R. The ARRIVE guidelines, a welcome improvement to standards for reporting animal research. J Gene Med. 2010; 12(7):559-60.

64. Kilkenny C, Browne WJ, Cuthill IC, Emerson M, Altman DG. Improving bioscience research reporting: the ARRIVE guidelines for reporting animal research. PLoS Biol. 2010;8(6):e1000412.

\section{Submit your next manuscript to BioMed Central and we will help you at every step:}

- We accept pre-submission inquiries

- Our selector tool helps you to find the most relevant journal

- We provide round the clock customer support

- Convenient online submission

- Thorough peer review

- Inclusion in PubMed and all major indexing services

- Maximum visibility for your research

Submit your manuscript at www.biomedcentral.com/submit 